\title{
Physiological and Genetically Engineered Expression Modulation Methods Do Not Affect Cellular Levels of the Heat Shock Protein HSP60 in Prostate Cancer Cells
}

\author{
HOLGER H.H. ERB ${ }^{1,2}$, ANDREAS STREITBÖRGER ${ }^{3}$, ALEXANDER MUSTEA $^{4}$ and MATTHIAS B. STOPE 2,4 \\ ${ }^{1}$ Department of Urology, University of Dresden, Dresden, Germany; \\ ${ }^{2}$ UroFors Consortium (Natural Scientists in Urological Research) \\ of the German Society of Urology, Dïsseldorf, Germany; \\ ${ }^{3}$ Urological Group Practice Randow and Streitbörger, Berlin, Germany; \\ ${ }^{4}$ Department of Gynecology and Gynecological Oncology, University Hospital Bonn, Bonn, Germany
}

\begin{abstract}
Background/Aim: Heat shock proteins (HSP) play a crucial role in the cellular responses during stressful conditions. In addition, HSP are involved in the regulation of a variety of important signaling pathways and processes as well as many pathological conditions, including cancer. In prostate cancer (PC), HSP60 is associated with poor differentiation and prognostic clinical parameters, such as high Gleason score, initial serum prostate-specific antigen levels, and lower cancer-specific survival. In this study, we investigated the regulation of $H S P 60$ protein in $P C$. Materials and Methods: LNCAP or PC3 cells were treated with androgens or transfected with vectors containing microRNA-1 (miR-1), HSP60, HSP60-specific short-hairpin RNA (shHSP60), or a miR-1 inhibitor. The change in HSP60 protein levels was examined using Western blot. Results: Treatment of PC cells with androgens did not alter the HSP60 protein levels. Modulation of miR-1 levels in LNCaP cells also did not affect the HSP60 protein. Furthermore, HSP60 levels could not be modified by overexpression or short hairpin RNA. Conclusion: It was found that neither physiological factors, such as androgens and the HSP6Ospecific miR-1, nor overexpression and knockdown systems could influence the HSP60 protein levels. These results suggest an essential role of HSP60 in PC cells, as its protein expression status is regulated very precisely.
\end{abstract}

This article is freely accessible online.

Correspondence to: Matthias Stope, Department of Gynecology and Gynecological Oncology, University Hospital Bonn, VenusbergCampus 1, 53127 Bonn, Germany. Tel: +49 22828711361, Fax: +49 22828716091, e-mail: matthias.stope@ukbonn.de

Key Words: HSP60 regulation, protein levels, expression regulation.
The members of the heat shock protein (HSP) family are induced under stress conditions, such as heat and cold shock, toxic agents, and UV radiation (1). However, in addition to their primarily cytoprotective function, HSPs also exert important roles in physiological signal transduction. For example, HSP27 can interact with transcription factors, such as the signal transducer and activator of transcription 5 (STAT5) and the androgen receptor (AR) and modulates their transcriptional activities $(2,3)$.

HSP60 is involved in numerous pathological processes, including inflammation, autoimmune diseases, neurodegenerative diseases, and cancer (4). The protein is primarily localized in mitochondria but is also found in the cytosol and other cell organelles $(4,5)$. Mitochondrial HSP60 is critical for maintaining the respiratory chain functionality and, thus, has essential roles in cellular energy metabolism $(5,6)$. In tumor tissues, HSP60 can be both upregulated (breast cancer, ovarian cancer) and downregulated (renal cell carcinoma, bladder cancer) (7-11) and elicit cytoprotective as well as proapoptotic cell responses $(12,13)$. In prostate cancer (PC), HSP60 expression correlates with poor differentiation and clinical parameters, such as Gleason score, serum prostatespecific antigen, and tumor-specific survival (7). Furthermore, HSP60 suppresses the activity of apoptosis-specific caspases and, thus, the induction of apoptosis (14).

The present study aimed to characterize the stability of HSP60 protein expression in an in vitro PC cell model. For this purpose, we attempted to modulate HSP60 expression levels by physiological noxious agents and genetic engineering techniques.

\section{Materials and Methods}

Cell culture. Human PC cells, $\mathrm{LNCaP}$ and PC3, were obtained from the American Type Culture Collection (ATCC, Rockville, USA) (15). The cells were cultured in RPMI 1640 medium (Life 
A

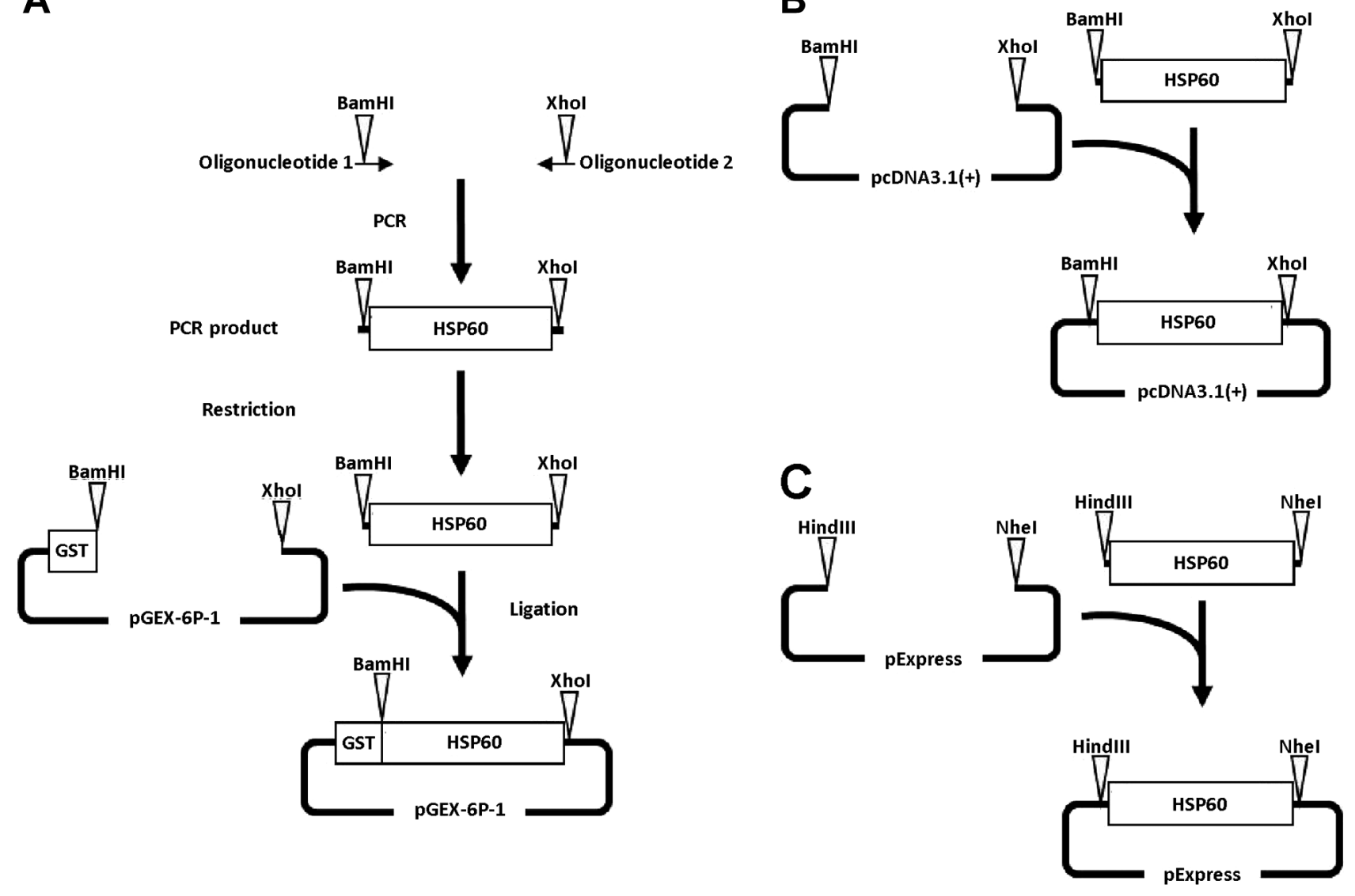

B

C

Figure 1. Cloning strategy of (A) pGEX-6P-1-HSP60, (B) pcDNA3.1(+)-HSP60, and (C) pExpress-HSP60.

Technologies, Darmstadt, Germany) supplemented with $10 \%$ fetal bovine serum (FBS), 20 mM HEPES-buffer, 1\% GlutaMax, and 1\% penicillin/streptomycin (Fisher Scientific, Schwerte, Germany) at $37^{\circ} \mathrm{C}$ and $5 \% \mathrm{CO}_{2}$. For stimulation with dihydrotestosterone (DHT), cells were incubated for $72 \mathrm{~h}\left(37^{\circ} \mathrm{C}, 5 \% \mathrm{CO}_{2}\right)$ in the presence of 10 $\mu \mathrm{M}$ DHT (Sigma-Aldrich, Munich, Germany).

Protein analysis. After the indicated incubation times, cells were harvested by treating with $100 \mu \mathrm{l}$ lysis buffer [50 mM Tris- $\mathrm{HCl}(\mathrm{pH}$ $6.8, \mathrm{v} / \mathrm{v}), 2 \%$ sodium dodecyl sulfate (w/v), $10 \%$ glycerol (v/v), $0.01 \%$ bromophenol blue (w/v), 5\% 2-mercaptoethanol (v/v)]. The protein lysate (20) $\mu \mathrm{l}$ was separated using sodium dodecyl sulfate (SDS)-polyacrylamide gel electrophoresis (Mini-Protean System, BioRad, München, Germany). The proteins were subsequently transferred to a Protean nitrocellulose membrane (Whatman, Dassel, Germany) using the semi-dry Trans-Blot SD transfer cell (BioRad). After blocking the membranes with Roti-block blocking solution (Carl Roth, Karlsruhe, Germany), proteins were detected using specific antibodies. Signals were visualized using SuperSignal West Dura chemiluminescent substrate (Thermo Scientific; Waltham, MA, USA) in a ChemiDoc system (BioRad) with Image Lab 5.1 beta software (BioRad). The antibodies that were used in this study are: HSP60 (D307) Antibody \#4870 (1:1,000, Cell Signaling \#2118 (1:10,000, Cell Signaling Technology); Anti-rabbit IgG, HRP-linked Antibody \#7074 (1:5,000, Cell Signaling Technology).

Cloning of HSP60-specific DNA vectors. To clone the full-length sequence of HSP60, total RNA was isolated from LNCaP cells (peqGOLD TriFast, Peqlab, Erlangen, Germany), transcribed into cDNA (RevertAid First Strand cDNA Synthesis Kit, Fermentas, St. Leon-Rot, Germany) and cloned into the DNA vector pGEX-6P-1 (NovoPro Bioscience, Shanghai, PR China; Figure 1A). HSP60 cDNA was amplified using specific oligonucleotides binding at the 5' end (5'AAAAGGATCCATGCTTCGGTTACCCACAGTC-3') and the 3' end (5'-AAAACTCGAGTTAGAACATGCCACCTCCCATAC-3') of the open reading frame of HSP60. The oligonucleotides contained specific recognition sites for restriction endonucleases (5' end: BamHI; 3' end: Xhol). The BamHI-HSP60-Xhol PCR product was double digested (BamHI/XhoI; Fermentas), purified (NucleoSpin Gel and PCR Cleanup Kit; Macherey-Nagel, Düren, Germany) and ligated (T4 DNA Ligase; Fermentas) into a BamHI/XhoI linearized pGEX-6P-1 vector. Vector amplification was carried out in transformed XL-1 Blue competent E. coli (Agilent Technologies, Santa Clara, CA, USA) propagated in Luria-Bertani (LB) medium containing $100 \mu \mathrm{g} / \mathrm{ml}$ ampicillin (Carl Roth). 
The HSP60 open reading frame sequence was re-cloned into eukaryotic expression vectors using the standard methods of recombinant DNA technology described above. For this purpose, the pGEX-6P-1-HSP60 vector DNA was digested with BamHI/XhoI and HindIII/NheI (all Fermentas) and cloned into the corresponding linearized vectors pcDNA3.1(+) (Thermo Scientific; Figure 1B) and pExpress (NovoPro Bioscience; Figure 1C), respectively.

For knockdown experiments, a customized HSP60-specific shRNA vector was constructed using the standard cloning methods described below. Two oligonucleotides containing the cDNA sequence of shHSP60 (5'-GATCCCCTGTACAAAGTAGAGAA GTATTCAAGAGATACTTCTCTACTTTGTACATTTTTA; 5'-TCG ATAAAAATGTACAAAGTAGAGAAGTATCTCTTGAATACTTC TCTACTTTGTACAGGG) were hybridized, resulting in overhangs that mimicked BglII- and Xhol-cleaved ends (Figure 2). After purification (NucleoSpin Gel and PCR Clean-up Kit; MachereyNagel), the hybridization product was ligated (T4 DNA Ligase; Fermentas) into a BglII/XhoI-digested pSuperior vector (OligoEngine, Seattle, WA, USA). DNA vector amplification was done in XL-1 Blue competent E. coli (Agilent Technologies) in LB Medium with $100 \mu \mathrm{g} / \mathrm{ml}$ ampicillin (Carl Roth) and the correct insert was verified using commercial sequencing (Qiagen, Hilden, Germany). For the overexpression of miR-1, the expression vector pmiR-1 was used (16).

Transfection experiments. For transfection, 150,000 cells/well were seeded into 6-well cell culture plates. Cells were transfected using Lipofectamine 2000 (Invitrogen, Karlsruhe, Germany) with a total amount of $5 \mu \mathrm{g}$ plasmid DNA or using siLentFect (BioRad) with 40 nM miR-1 inhibitor (Qiagen), respectively. Empty vectors, pcDNA3.1(+) (Thermo Scientific), pExpress (NovoPro Bioscience), and pSuperior (OligoEngine), served as control.

Statistics. Statistical analyses were conducted using the unpaired Student's t-test. Data are expressed as mean $\pm \mathrm{SD}$, and results of $\mathrm{p}<0.05$ were considered significant.

\section{Results}

As androgens play a critical role in $\mathrm{PC}$, we investigated the influence of DHT on HSP60 protein expression. For this purpose, following treatment of $\mathrm{LNCaP}$ and PC-3 cells with 10 $\mu \mathrm{M}$ DHT for $48 \mathrm{~h}$ alterations in intracellular HSP60 levels were examined by Western blot (Figure 3A). Quantification of the results showed only highly modest and statistically insignificant changes in the HSP60 expression in the presence of DHT.

Besides hormones, microRNAs are also critical regulators of cell physiology by controlling the translation or stability of their target proteins (17). For example, MicroRNA miR1 has been described as a direct regulator of the HSP60 expression in cardiomyocytes (18). To evaluate whether miR-1 also controls the HSP60 expression in PC cells, transfection experiments were performed using a specific miR-1 inhibitor and a miR-1 overexpression vector. Our analysis showed that both inhibition and overexpression of miR-1 did not affect cellular HSP60 protein levels in PC cells (Figure 3B).

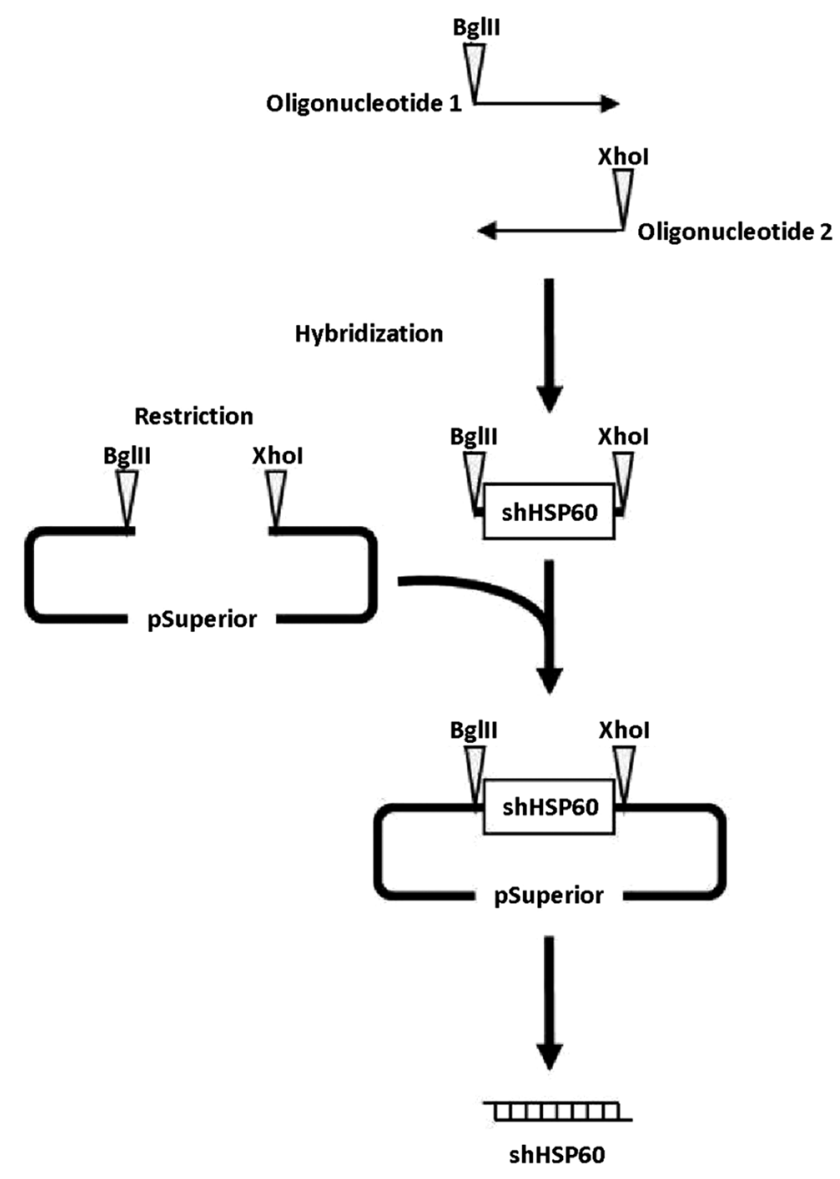

Figure 2. Cloning strategy of pSuperior-shHSP60.

Since affecting physiological factors did not cause detectable alterations in HSP60 expression, we attempted to modulate HSP60 levels using genetic engineering. Two established overexpression vectors [pcDNA3.1(+) and pExpress] as well as a knockdown vector, optimized for the expression of short shRNA (pSuperior), were used for this purpose. The custom cloned HSP60-specific vectors were transfected into LNCaP cells and intracellular HSP60 protein levels were measured. In the first $24 \mathrm{~h}$ following pcDNA3.1(+)-HSP60 transfection, there was a tendential but insignificant increase in HSP60 expression (Figure 4A), however, this could not be confirmed $48 \mathrm{~h}$ and $72 \mathrm{~h}$ after transfection. The use of the vector pExpress-HSP60 also did not lead to an increase in HSP60 levels (Figure $4 \mathrm{~B})$. In a vice versa approach, we pursued the downregulation of HSP60 expression, by transfecting PC cells with the HSP60 knockdown vector pSuperiorshHSP60. Interestingly, no decrease in intracellular HSP60 levels could be detected during the incubation period (Figure 4C). 

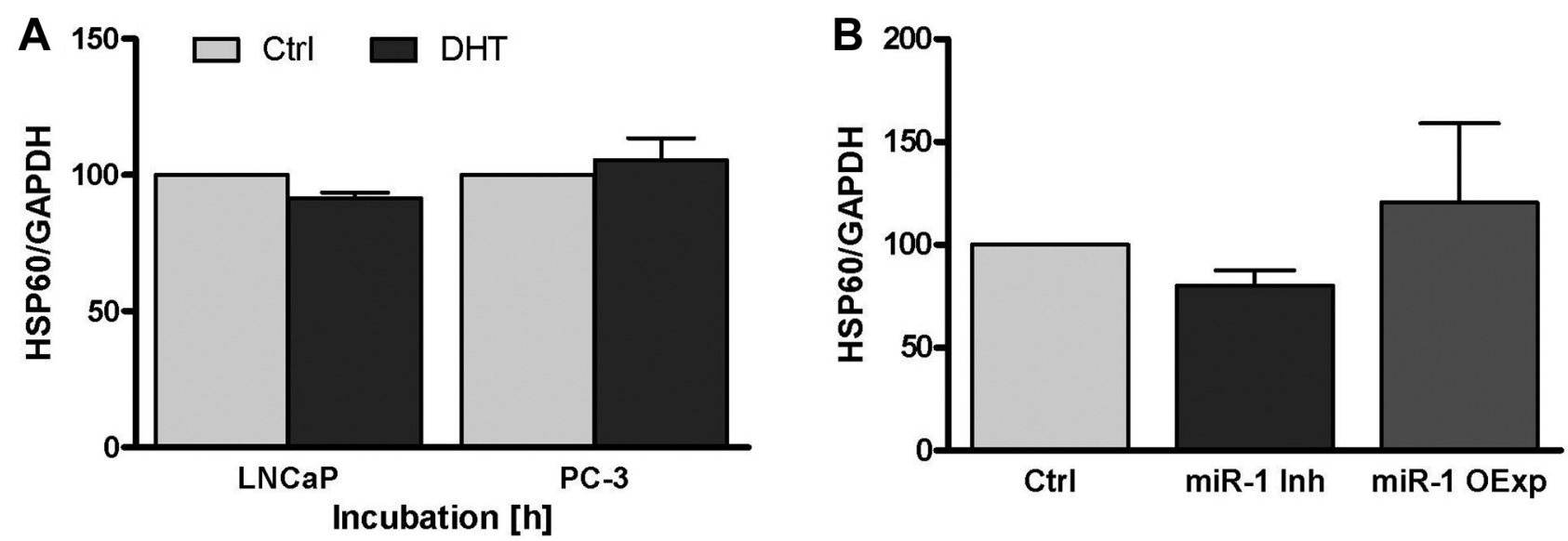

Figure 3. DHT and miR-1 have no effect on HSP60 protein levels in PC cells. Relative HSP60 Western blot analysis of (A) LNCaP and PC-3 cells after incubation with $10 \mu \mathrm{M} \mathrm{DHT}$ and (B) LNCaP cells after inhibition (miR-1 Inh) and overexpression (miR-1 OExp) of the regulatory microRNA miR-1. HSP60 expression was normalized to the reference protein GAPDH and presented as mean \pm SD. All experiments were performed at least 3 times.

\section{Discussion}

The primary function of HSPs is to protect cells under sublethal stress (19). In addition, members of the HSP family have been associated with cancer growth as they can promote tumor cell proliferation and inhibit cellular death pathways. High expression of HSP27 and HSP70 have, in addition, been associated with drug resistance as well (20). In PC, HSP27 levels increase following androgen ablation, and high HSP27 levels promote the development of castration-resistant PC (21). Increased HSP27 and HSP60 protein expression has also been identified as a predictor of biochemical recurrence after radical prostatectomy, and modulation of HSP expression has been discussed as a potential new therapeutic approach to control tumor cell proliferation, including improved survival (22, 23). Suppression of HSP27 leads to the downregulation of AR in PC cells and, thus, inhibits its oncogenic activity (2). An increase in HSP60 has also been found in PC, especially in patients with poor prognosis $(7,22,23)$. Taken together, these data suggest that HSP60 could also be a potential therapeutic target in these patients. This study, however, indicates that, unlike HSP27, the protein expression of HSP60 is probably not controlled by androgens (21). Because androgens primarily regulate tissue-specific genes, this finding suggests that HSP60 plays a general role in cell homeostasis. In addition, there are no data that other therapeutic agents affect HSP60 protein levels in PC or even other tumors, such as ovarian cancer, osteosarcoma, and bladder cancer (24-27). Despite this, there is strong evidence that HSP60 is upregulated in chemoresistant tumor cells and is involved in ovarian cancer chemo resistance $(14,28)$.
One of the direct regulators of HSP60 is miR-1, with even low miR-1 levels being related to recurrent PC $(18,29,30)$. Consistent with the low miR-1 expression, increased HSP60 protein has been correlated with the biochemical recurrence of PC $(7,22,23)$. Thus, it can be suggested that miR-1 regulation plays a role in altering HSP60 protein levels in PC. However, direct regulation of HSP60 by mir-1 was not detected in the PC cell line LNCaP. The fact that the protein levels did not change after treatment with an intrinsic HSP60 regulator suggests a robust regulatory mechanism that maintains HSP60 protein levels at a constant level, possibly using an alternative pathway in the presence of miR1. This steady-state regulation for constantly expressing a protein with pivotal function has also been previously demonstrated for other factors, such as tumor suppressor p53, thiamine thiazole synthase (THI1), and genomes uncoupled 4 (GUN5) (31-33).

Since our effort to regulate HSP60 protein levels using physiological factors had no effect, we used genetic engineering. Using two different overexpression systems, however, detected no significant changes in the HSP60 protein levels. Because both expression systems are based on the cytomegalovirus (CMV) promoter, which is considered as one of the strongest promoters in vitro, this result suggests a strong counter-regulation of HSP60 upon its overexpression (34). However, there is a possibility that the CMV promoter is silenced in cancer cells (35). Therefore, an HSP60-specific shRNA was expressed in LNCaP cells, controlled by an H1 RNA polymerase III promoter. This knockdown approach also showed no alteration in HSP60 expression. However, it was striking that similar to $24 \mathrm{~h}$ after transfection of the pcDNA3.1(+)-HSP60 overexpression vector, a trend towards a decrease in HSP60 level was also 

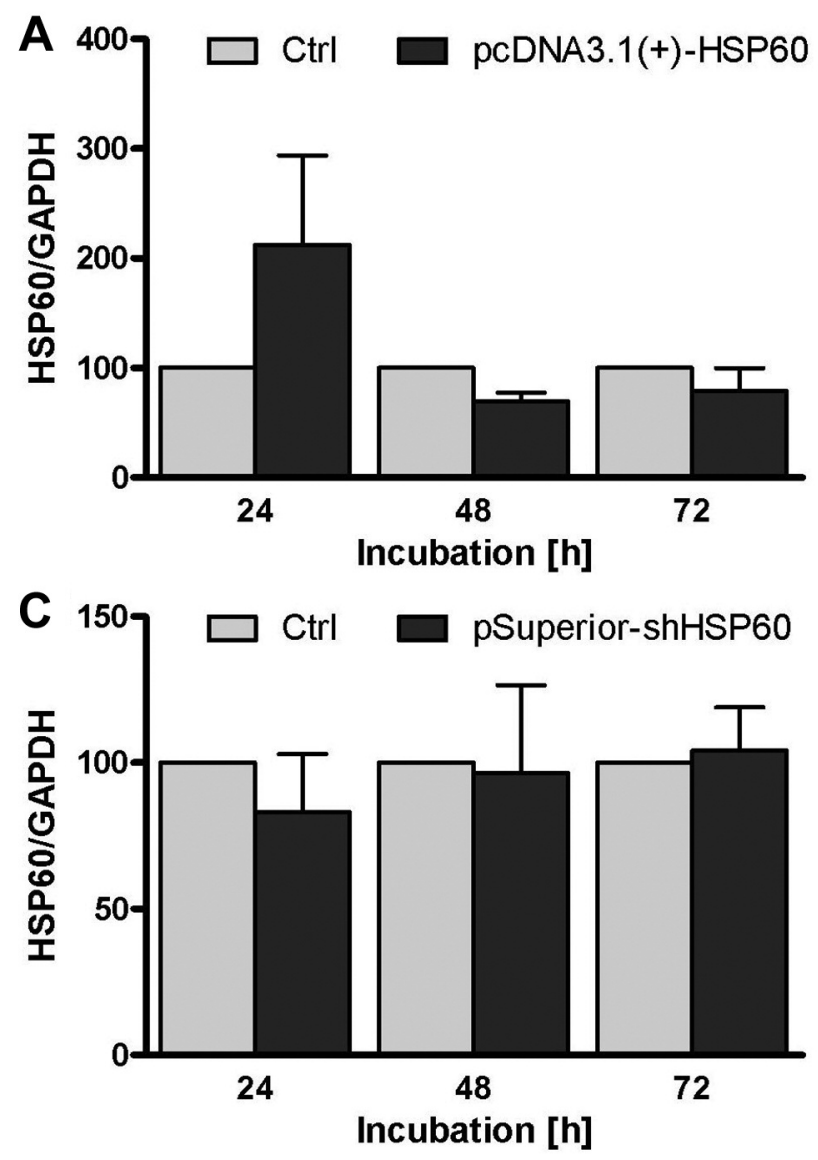

observed $24 \mathrm{~h}$ following the knockdown approach. This result could imply that the genetically engineered modulation of HSP60 expression is very rapidly counter-regulated.

Li et al. have used synthetic double-stranded siRNA molecules directed against HSP60 mRNA, transfected into rat pancreatic tissue cells (36). Although a significant reduction of HSP60 mRNA to 0.5 -fold was exhibited, at the protein level the down-regulation was only about 0.7 -fold of the control approach. In breast cancer cells, a modest suppression of HSP60 expression was also detectable after transfection with commercial HSP60-specific siRNA molecules, but the authors did not quantify and statistically analyze their data (37). In the case of the pSuperior-shHSP60 vector used in the present study, it cannot be excluded that the effect of the HSP60-specific shRNA was not efficient enough. miR-1 is a specific physiological repressor of HSP60 expression (18). Using the miR-1 overexpression vector pmiR-1, which is also based on pSuperior, no downregulation of HSP60 protein expression was demonstrated either. Since the sequences of the pSuperior constructs for the knockdown of HSP60 as well as for the expression of miR-1 were verified by sequencing, sequence

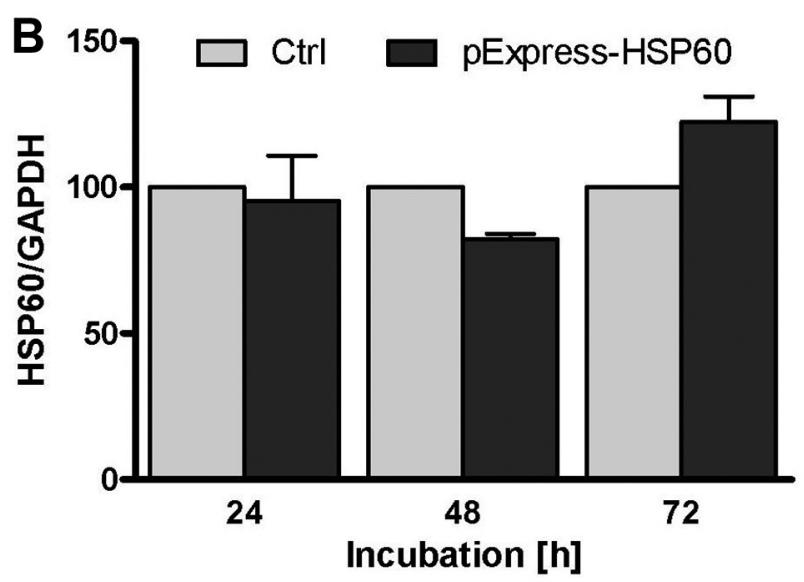

Figure 4. The genetically engineered modulation of HSP60 expression by short hairpin RNA technology did not affect intracellular HSP6O levels in LNCaP cells. Relative HSP60 Western blot analysis of LNCaP cells after transfection with (A) the HSP60 overexpression vectors pcDNA3.1(+)-HSP60 (B) and pExpress-HSP60 (C) and the HSP60 knockdown vector pSuperior-shHSP60. HSP60 expression was normalized to the reference protein GAPDH and presented as mean $\pm S D$.

errors in the regulatory and coding regions of the DNA plasmids can be excluded. Furthermore, the RNA expression system pSuperior is an established commercial vector that has also been frequently used successfully by our group for expression modulation $(16,38-42)$. The protein overexpression vectors pcDNA3.1(+) and pExpress used for overexpression of HSP60 are also well-characterized and very effective protein expression systems. Nevertheless, neither overexpression system showed significant upregulation of HSP60 synthesis in PC cells. This result supports the hypothesis that constant HSP60 expression in PC cells is important for cellular physiology and is, therefore, very tightly regulated.

In this study, HSP60 protein regulation was investigated in different PC cell lines. It was found that neither physiological factors, such as androgens and the HSP60specific miR-1, nor overexpression and knockdown systems could influence its protein levels. These data may indicate that a constant expression level of HSP60 protein in progression in PC is important for cell malignancy. Deviations from this constant expression level appear to be counter regulated by as yet unknown cellular mechanisms. 


\section{Conflicts of Interest}

The Authors declare that they have no competing interests.

\section{Authors' Contributions}

Conceptualization: HHHE, MBS; methodology: HHHE, AS; formal analysis: HHHE, AS, AM, MBS; supervision: AM, MBS; writing original draft: HHHE, MBS; original draft review and editing: HHHE, AM, MBS.

\section{References}

1 Jolly C and Morimoto RI: Role of the heat shock response and molecular chaperones in oncogenesis and cell death. J Natl Cancer Inst 92(19): 1564-1572, 2000. PMID: 11018092. DOI: 10.1093/jnci/92.19.1564

2 Stope MB, Schubert T, Staar D, Rönnau C, Streitbörger A, Kroeger N, Kubisch C, Zimmermann U, Walther R and Burchardt M: Effect of the heat shock protein HSP27 on androgen receptor expression and function in prostate cancer cells. World J Urol 30(3): 327-331, 2012. PMID: 22362414. DOI: $10.1007 / \mathrm{s} 00345-012-0843-\mathrm{z}$

3 Sevin M, Kubovcakova L, Pernet N, Causse S, Vitte F, Villeval JL, Lacout C, Cordonnier M, Rodrigues-Lima F, Chanteloup G, Mosca M, Chrétien ML, Bastie JN, Audia S, Sagot P, Ramla S, Martin L, Gleave M, Mezger V, Skoda R, Plo I, Garrido C, Girodon F and de Thonel A: HSP27 is a partner of JAK2-STAT5 and a potential therapeutic target in myelofibrosis. Nat Commun 9(1): 1431, 2018. PMID: 29650953. DOI: 10.1038/s41467-01803627-9

4 Caruso Bavisotto C, Alberti G, Vitale AM, Paladino L, Campanella C, Rappa F, Gorska M, Conway de Macario E, Cappello F, Macario AJL and Marino Gammazza A: Hsp60 posttranslational modifications: functional and pathological consequences. Front Mol Biosci 7: 95, 2020. PMID: 32582761. DOI: $10.3389 /$ fmolb.2020.00095

5 Cappello F, Conway de Macario E, Marasà L, Zummo G and Macario AJ: Hsp60 expression, new locations, functions and perspectives for cancer diagnosis and therapy. Cancer Biol Ther 7(6): 801-809, 2008. PMID: 18497565. DOI: 10.4161/cbt.7.6.6281

6 Bie AS, Cömert C, Körner R, Corydon TJ, Palmfeldt J, Hipp MS, Hartl FU and Bross P: An inventory of interactors of the human HSP60/HSP10 chaperonin in the mitochondrial matrix space. Cell Stress Chaperones 25(3): 407-416, 2020. PMID: 32060690. DOI: 10.1007/s12192-020-01080-6

7 Castilla C, Congregado B, Conde JM, Medina R, Torrubia FJ, Japón MA and Sáez C: Immunohistochemical expression of Hsp60 correlates with tumor progression and hormone resistance in prostate cancer. Urology 76(4): 1017.e1-1017.e6, 2010. PMID: 20708221. DOI: 10.1016/j.urology.2010.05.045

8 Desmetz C, Bibeau F, Boissière F, Bellet V, Rouanet $\mathrm{P}$, Maudelonde T, Mangé A and Solassol J: Proteomics-based identification of HSP60 as a tumor-associated antigen in early stage breast cancer and ductal carcinoma in situ. J Proteome Res 7(9): 3830-3837, 2008. PMID: 18683965. DOI: 10.1021/ pr800130d

9 Guo J, Li X, Zhang W, Chen Y, Zhu S, Chen L, Xu R, Lv Y, Wu D, Guo M, Liu X, Lu W and Deng H: HSP60-regulated mitochondrial proteostasis and protein translation promote tumor growth of ovarian cancer. Sci Rep 9(1): 12628, 2019. PMID: 31477750. DOI: 10.1038/s41598-019-48992-7

10 Tang H, Chen Y, Liu X, Wang S, Lv Y, Wu D, Wang Q, Luo M and Deng H: Downregulation of HSP60 disrupts mitochondrial proteostasis to promote tumorigenesis and progression in clear cell renal cell carcinoma. Oncotarget 7(25): 38822-38834, 2016. PMID: 27246978. DOI: 10.18632/oncotarget.9615

11 Lebret T, Watson RW, Molinié V, O'Neill A, Gabriel C, Fitzpatrick JM and Botto H: Heat shock proteins HSP27, HSP60, HSP70, and HSP90: expression in bladder carcinoma. Cancer 98(5): 970-977, 2003. PMID: 12942564. DOI: 10.1002/ cncr.11594

12 Chandra D, Choy G and Tang DG: Cytosolic accumulation of HSP60 during apoptosis with or without apparent mitochondrial release: evidence that its pro-apoptotic or pro-survival functions involve differential interactions with caspase-3. J Biol Chem 282(43): 31289-31301, 2007. PMID: 17823127. DOI: 10.1074/ jbc.M702777200

13 Sun B, Li G, Yu Q, Liu D and Tang X: HSP60 in cancer: a promising biomarker for diagnosis and a potentially useful target for treatment. J Drug Target 30(1): 31-45, 2022. PMID: 33939586. DOI: 10.1080/1061186X.2021.1920025

14 Kumar S, O'Malley J, Chaudhary AK, Inigo JR, Yadav N, Kumar R and Chandra D: Hsp60 and IL-8 axis promotes apoptosis resistance in cancer. Br J Cancer 121(11): 934-943, 2019. PMID: 31673102. DOI: 10.1038/s41416-019-0617-0

15 Erb HHH, Culig Z and Stope MB: IL-4 counteracts the cytotoxic effects of peripheral blood mononuclear cells on hormonesensitive prostate cancer cells. In Vivo 35(4): 1973-1977, 2021. PMID: 34182471. DOI: 10.21873/invivo.12465

16 Stope MB, Stender C, Schubert T, Peters S, Weiss M, Ziegler P, Zimmermann U, Walther $\mathrm{R}$ and Burchardt $\mathrm{M}$ : Heat-shock protein HSPB1 attenuates microRNA miR-1 expression thereby restoring oncogenic pathways in prostate cancer cells. Anticancer Res 34(7): 3475-3480, 2014. PMID: 24982356.

17 Filipowicz W, Bhattacharyya SN and Sonenberg N: Mechanisms of post-transcriptional regulation by microRNAs: are the answers in sight? Nat Rev Genet 9(2): 102-114, 2008. PMID: 18197166. DOI: $10.1038 / \mathrm{nrg} 2290$

18 Shan ZX, Lin QX, Deng CY, Zhu JN, Mai LP, Liu JL, Fu YH, Liu XY, Li YX, Zhang YY, Lin SG and Yu XY: miR-1/miR206 regulate Hsp60 expression contributing to glucosemediated apoptosis in cardiomyocytes. FEBS Lett 584(16): 3592-3600, 2010. PMID: 20655308. DOI: 10.1016/j.febslet. 2010.07.027

19 Soo ET, Yip GW, Lwin ZM, Kumar SD and Bay BH: Heat shock proteins as novel therapeutic targets in cancer. In Vivo 22(3): 311-315, 2008. PMID: 18610741.

20 Vargas-Roig LM, Gago FE, Tello O, Aznar JC and Ciocca DR: Heat shock protein expression and drug resistance in breast cancer patients treated with induction chemotherapy. Int J Cancer 79(5): 468-475, 1998. PMID: 9761114. DOI: 10.1002/ (sici)1097-0215(19981023)79:5<468::aid-ijc4>3.0.co;2-z

21 Rocchi P, So A, Kojima S, Signaevsky M, Beraldi E, Fazli L, Hurtado-Coll A, Yamanaka K and Gleave M: Heat shock protein 27 increases after androgen ablation and plays a cytoprotective role in hormone-refractory prostate cancer. Cancer Res 64(18): 6595-6602, 2004. PMID: 15374973. DOI: 10.1158/00085472.CAN-03-3998 
22 Glaessgen A, Jonmarker S, Lindberg A, Nilsson B, Lewensohn R, Ekman P, Valdman A and Egevad L: Heat shock proteins 27, 60 and 70 as prognostic markers of prostate cancer. APMIS 116(10): 888-895, 2008. PMID: 19132982. DOI: 10.1111/j.16000463.2008.01051.x

23 Cornford PA, Dodson AR, Parsons KF, Desmond AD, Woolfenden A, Fordham M, Neoptolemos JP, Ke Y and Foster CS: Heat shock protein expression independently predicts clinical outcome in prostate cancer. Cancer Res 60(24): 70997105, 2000. PMID: 11156417.

24 Abazid A, Martin B, Choinowski A, McNeill RV, Brandenburg LO, Ziegler P, Zimmermann U, Burchardt M, Erb H and Stope MB: The androgen receptor antagonist enzalutamide induces apoptosis, dysregulates the heat shock protein system, and diminishes the androgen receptor and estrogen receptor $\beta 1$ expression in prostate cancer cells. J Cell Biochem 120(10): 16711-16722, 2019. PMID: 31297844. DOI: 10.1002/jcb.28929

25 Rottach AM, Ahrend H, Martin B, Walther R, Zimmermann U, Burchardt $\mathrm{M}$ and Stope MB: Cabazitaxel inhibits prostate cancer cell growth by inhibition of androgen receptor and heat shock protein expression. World J Urol 37(10): 2137-2145, 2019. PMID: 30603780. DOI: 10.1007/s00345-018-2615-x

26 Kimura E, Enns RE, Thiebaut F and Howell SB: Regulation of HSP60 mRNA expression in a human ovarian carcinoma cell line. Cancer Chemother Pharmacol 32(4): 279-285, 1993. PMID: 8100743. DOI: $10.1007 / \mathrm{BF} 00686173$

27 Gorska M, Marino Gammazza A, Zmijewski MA, Campanella C, Cappello F, Wasiewicz T, Kuban-Jankowska A, Daca A, Sielicka A, Popowska U, Knap N, Antoniewicz J, Wakabayashi $\mathrm{T}$ and Wozniak M: Geldanamycin-induced osteosarcoma cell death is associated with hyperacetylation and loss of mitochondrial pool of heat shock protein 60 (hsp60). PLoS One 8(8): e71135, 2013. PMID: 24015183. DOI: 10.1371/journal. pone .0071135

28 Harper AK, Fletcher NM, Fan R, Morris RT and Saed GM: Heat shock protein 60 (HSP60) serves as a potential target for the sensitization of chemoresistant ovarian cancer cells. Reprod Sci 27(4): 1030-1036, 2020. PMID: 32124395. DOI: 10.1007/ s43032-019-00089-2

29 Karatas OF, Guzel E, Suer I, Ekici ID, Caskurlu T, Creighton CJ, Ittmann $M$ and Ozen $M$ : miR-1 and miR-133b are differentially expressed in patients with recurrent prostate cancer. PLoS One 9(6): e98675, 2014. PMID: 24967583. DOI: 10.1371/ journal.pone.0098675

30 Weiss M, Brandenburg LO, Burchardt $\mathrm{M}$ and Stope MB: MicroRNA-1 properties in cancer regulatory networks and tumor biology. Crit Rev Oncol Hematol 104: 71-77, 2016. PMID: 27286699. DOI: 10.1016/j.critrevonc.2016.05.014

31 Nelson CJ, Alexova R, Jacoby RP and Millar AH: Proteins with high turnover rate in barley leaves estimated by proteome analysis combined with in planta isotope labeling. Plant Physiol 166(1): 91-108, 2014. PMID: 25082890. DOI: 10.1104/pp. 114.243014

32 Chao CC: Mechanisms of p53 degradation. Clin Chim Acta 438: 139-147, 2015. PMID: 25172038. DOI: 10.1016/j.cca.2014. 08.015
33 Banaszynski LA, Chen LC, Maynard-Smith LA, Ooi AG and Wandless TJ: A rapid, reversible, and tunable method to regulate protein function in living cells using synthetic small molecules. Cell 126(5): 995-1004, 2006. PMID: 16959577. DOI: 10.1016/j.cell.2006.07.025

34 Boshart M, Weber F, Jahn G, Dorsch-Häsler K, Fleckenstein B and Schaffner W: A very strong enhancer is located upstream of an immediate early gene of human cytomegalovirus. Cell 41(2): 521-530, 1985. PMID: 2985280. DOI: 10.1016/s00928674(85)80025-8

35 Teschendorf C, Warrington KH Jr, Siemann DW and Muzyczka $\mathrm{N}$ : Comparison of the EF-1 alpha and the CMV promoter for engineering stable tumor cell lines using recombinant adenoassociated virus. Anticancer Res 22(6A): 3325-3330, 2002. PMID: 12530082.

36 Li YY, Lu S, Li K, Feng JY, Li YN, Gao ZR and Chen CJ: Down-regulation of HSP60 expression by RNAi increases lipopolysaccharide- and cerulein-induced damages on isolated rat pancreatic tissues. Cell Stress Chaperones 15(6): 965-975, 2010. PMID: 20574674. DOI: 10.1007/s12192-010-0207-9

37 Ghosh JC, Dohi T, Kang BH and Altieri DC: Hsp60 regulation of tumor cell apoptosis. J Biol Chem 283(8): 5188-5194, 2008. PMID: 18086682. DOI: 10.1074/jbc.M705904200

38 Stope MB, Hettenbach D, Kaul A, Paditz M, Diesing K, Burchardt M, Zygmunt M, Mustea A and Koensgen D: The tumor suppressor microRNA-1 exhibits restricted inhibition of proliferation of ovarian cancer cells. Anticancer Res 36(7): 3329-3334, 2016. PMID: 27354590.

39 Stope MB, Cernat V, Kaul A, Diesing K, Koensgen D, Burchardt $\mathrm{M}$ and Mustea A: Functionality of the tumor suppressor microRNA-1 in malignant tissue and cell line cells of uterine leiomyosarcoma. Anticancer Res 38(3): 1547-1550, 2018. PMID: 29491084. DOI: 10.21873/anticanres.12383

40 Reuter A, Sckell A, Brandenburg LO, Burchardt M, Kramer A and Stope MB: Overexpression of microRNA-1 in prostate cancer cells modulates the blood vessel system of an in vivo hen's egg test-chorioallantoic membrane model. In Vivo 33(1): 41-46, 2019. PMID: 30587600. DOI: 10.21873/invivo.11436

41 Stope MB, Peters S, Großebrummel H, Zimmermann U, Walther $\mathrm{R}$ and Burchardt M: Androgen receptor (AR) inhibitor ErbB3binding protein-1 (Ebp1) is not targeted by the newly identified AR controlling signaling axis heat-shock protein HSP27 and microRNA miR-1 in prostate cancer cells. World J Urol 33(3): 323-327, 2015. PMID: 24798454. DOI: 10.1007/s00345-0141307-4

42 Stope MB, Bradl J, Peters S, Streitbörger A, Weiss M, Zimmermann U, Walther R, Lillig CH and Burchardt M: Shortened isoforms of the androgen receptor are regulated by the cytoprotective heat-shock protein HSPB1 and the tumorsuppressive microRNA miR-1 in prostate cancer cells. Anticancer Res 33(11): 4921-4926, 2013. PMID: 24222130.

Received October 29, 2021

Revised January 13, 2022 Accepted January 28, 2022 